\title{
RESEARCH AND GRADUATE EDUCATION: A GLOBAL WORLD DURING TROUBLED TIMES
}

\author{
James A. Guikema \\ Associate Dean of the Graduate School \\ Associate Vice Provost for Graduate Research \\ Kansas State University
}

The theme for this meeting is timely. Since I serve the Kansas State Graduate School, I wish to focus my time and thoughts on the impact that the events of 9-11 may have on the research and graduate education enterprise.

Interestingly, just as the events of 9-11 were unfolding, the National Science Board was about to release a document titled Toward a More Effective Role for the U.S. Government in International Science and Engineering. The prologue states that "the recommendations of this report, developed over the past year, remain as relevant as before September 11, and their implementation even more compelling." The underlying theme is cooperation in science and engineering - bilateral and multilateral. Such cooperation builds a universal culture in science by promoting objectivity, tolerance, integrity, and free inquiry.

The National Science Board further suggests that the U.S. government should work toward a more effective, coordinated framework for global research and graduate education. Twentieth-century problems require a global approach in seeking solutions. For example, a regional or national perspective cannot meaningfully address the extent and significance of global warming. Human health and the spread of infectious diseases are issues that cross the borders of countries.

The globalization of university science and technology is a real phenomenon. This development could be at risk because of the policies enforced following 9-11. There are several examples at Kansas State University. For example, expertise in grassland biology, generated by decades of research on the Konza Prairie Biological Station, extends now to the savannahs of subSaharan Africa through the NSF International Long Term Ecological Research Program (ILTER). Furthermore, educational projects link Manhattan, Kansas with sister sites in the Russian Federation. Gravitational biology projects funded by NASA have K-State investigators partnering with colleagues in the Ukraine. The K-State presence in international agriculture has been a long-standing strength.

A decade ago, only about $10 \%$ of all publications by U.S. investigators involved international collaboration. As of 1999, it had increased to more than $20 \%$. Physics, earth and space science, and mathematics showed the largest 
globalization, with over $30 \%$ of the publications by U.S. investigators documenting an international collaboration.

The science and engineering workforce in the U.S. reflects globalization as well. Over $20 \%$ of the Ph.D. scientists and engineers in U.S. academic employment are foreign-born. This figure tops $30 \%$ for engineering and computer sciences. Employment in industry is even more striking. Over $30 \%$ of the Ph.D. scientists and engineers in industry are foreign-born, with engineering and computer sciences nearing $50 \%$.

It is not surprising that the enterprise of educating graduate students is international. The number of doctorates in science and engineering earned by non-U.S. citizens rose from under 4,000 in 1980 to over 11,000 in 1995. The U.S. is not alone in this phenomenon. In $1999,49 \%$ of the doctorates earned in the U.S. were awarded to international students, while in the United Kingdom, the percentage was $44 \%$, Japan $43 \%$, and France $30 \%$.

In preparation for this meeting, I located the most recent Department of Education numbers for the degrees granted by the institutions represented here. These are shown in Figure 1, and contrast doctorates awarded in 1990 with 2000. Our graduate student clientele mirrors the profile at the national level. Well over $30 \%$ of the total doctorates earned at our institutions were by international students. The profile becomes even more interesting when looking at the School of Education (where 10\% of the doctoral students are international) as compared with Engineering (over 70\%).

Can the events of 9-11 have an impact on such a healthy, global graduate research/education enterprise? The answer is yes, in both positive and negative ways.

The federal government will likely take control and focus funding in relevant areas. The biology of infectious disease will probably see funding increases, and will focus on diseases that are emerging and not currently endemic in the U.S. I imagine that this will promote international cooperation between U.S. investigators and researchers in countries that currently have these diseases.

Hopefully, 9-11 events will serve as a wake-up call to our young American student colleagues. Interest in careers requiring doctorates in the sciences and engineering has been declining among Americans. This is a major issue to be addressed.

With increased funding for research, and with (hopefully) a renewed domestic interest in research activities, comes an increased regulatory burden for the research administrator. Laboratory security costs will soar. International 
students may experience increased difficulty in obtaining visas to permit their study in the U.S. This has been observed already.

The enhanced reporting system that the federal government now requires is another daunting issue in graduate education post 9-11. The Student and Exchange Visitor Information System (SEVIS) is scheduled to come online during the Fall 2002 by the Immigration and Naturalization Service (INS). SEVIS shifts the burden of maintaining and updating information about our graduate students from a student/INS interchange to a student/university/INS interchange, and triples the number of data items that a student must report. Universities will be responsible for reporting changes in a student's status to INS with a very short deadline. All of this by Fall 2002, and INS only recently published the format of their database, such that software vendors can only now begin to develop the tools we will need in the university/INS linkage. And expensive tools they will be. Many graduate schools and foreign student advisors across the nation view SEVIS as a speeding freight train - with the school administration and the advisor right in the middle of the railroad tracks.

Regardless of the challenges before us, the institutions represented at this conference have programs for research and graduate education that will remain robust and international. 

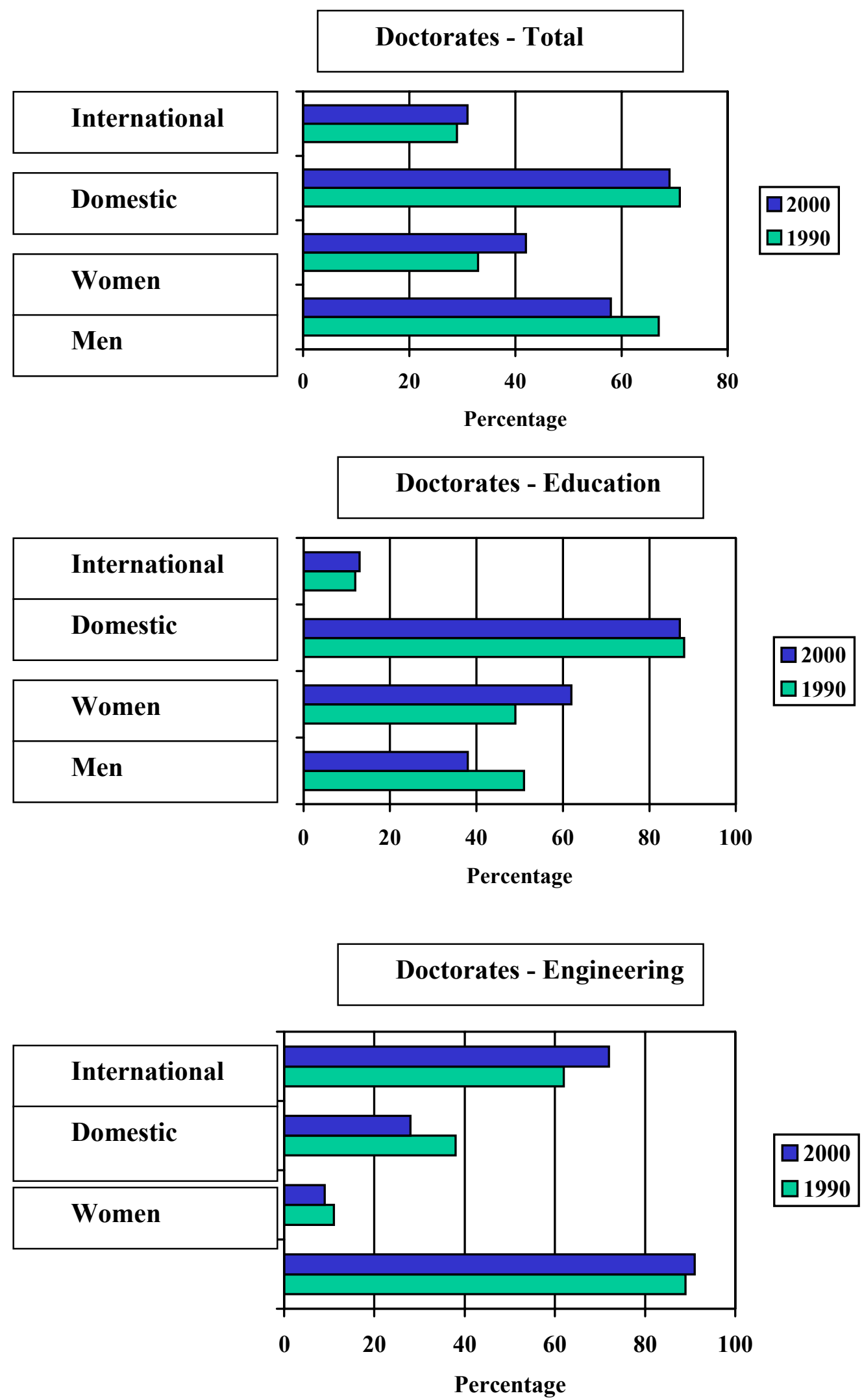

Figure 1. Profiles of the doctorates awarded from the universities represented at the Merrill Conference in 1990 and 2000. 